\title{
Assessment of Hazards in Gas Hydrates Recovery
}

\author{
Chinedu E. Ejike \\ Department of Petroleum Engineering, Federal University of Technology Owerri, Owerri, Nigeria \\ Email: ejikechinedu@gmail.com
}

How to cite this paper: Ejike, C.E. (2019) Assessment of Hazards in Gas Hydrates Recovery. Open Journal of Yangtze Gas and Oil, 4, 231-239.

https://doi.org/10.4236/ojogas.2019.44018

Received: June 25, 2019

Accepted: August 4, 2019

Published: August 7, 2019

Copyright $\odot 2019$ by author(s) and Scientific Research Publishing Inc. This work is licensed under the Creative Commons Attribution International License (CC BY 4.0).

http://creativecommons.org/licenses/by/4.0/

\begin{abstract}
Gas hydrates are whitish balls containing enormous amount of methane gas at deep marine sediments. This energy source will account for future energy needs as it is said to be twice the value of all recoverable energy sources tapped till date. They are formed as a result of biogenic and thermogenic matters coupled with deep water conditions such as excessive pressure and diminishing temperature. Various recovery methods have been juxtaposed till date to influence the production of its reserves. However, appropriate assessment of the hazards and shortcomings hindering the large scale production of these reserve needs to be checkmated in order to facilitate the effective development of gas from methane hydrate in a near future.
\end{abstract}

\section{Keywords}

Methane Gas, Hydrates, Hazards, Recovery, Unconventional Energy

\section{Introduction}

As human population increases daily, it demands a proportional increase in our energy needs. There's utmost concern for an energy source which can counter future energy needs in order to ensure economic sustainability and development. Gas hydrates are unconventional energy sources containing huge deposit of methane gas at permafrost and ocean sediments. This enormous gas is embedded by solid water lattice at varying subsurface depth just as the yolk is enclosed by the albumen of an egg shell. This helps to ensure the stability of the methane gas. Gas hydrate is an important subject of many countries' research since its discovery because of its potential positive impact and its commercial deposits. Some of these countries include: Japan, China, Korea, Canada, Ameri$\mathrm{ca}$, and India among others, the locations of methane hydrates around the globe are shown in Figure 1. 


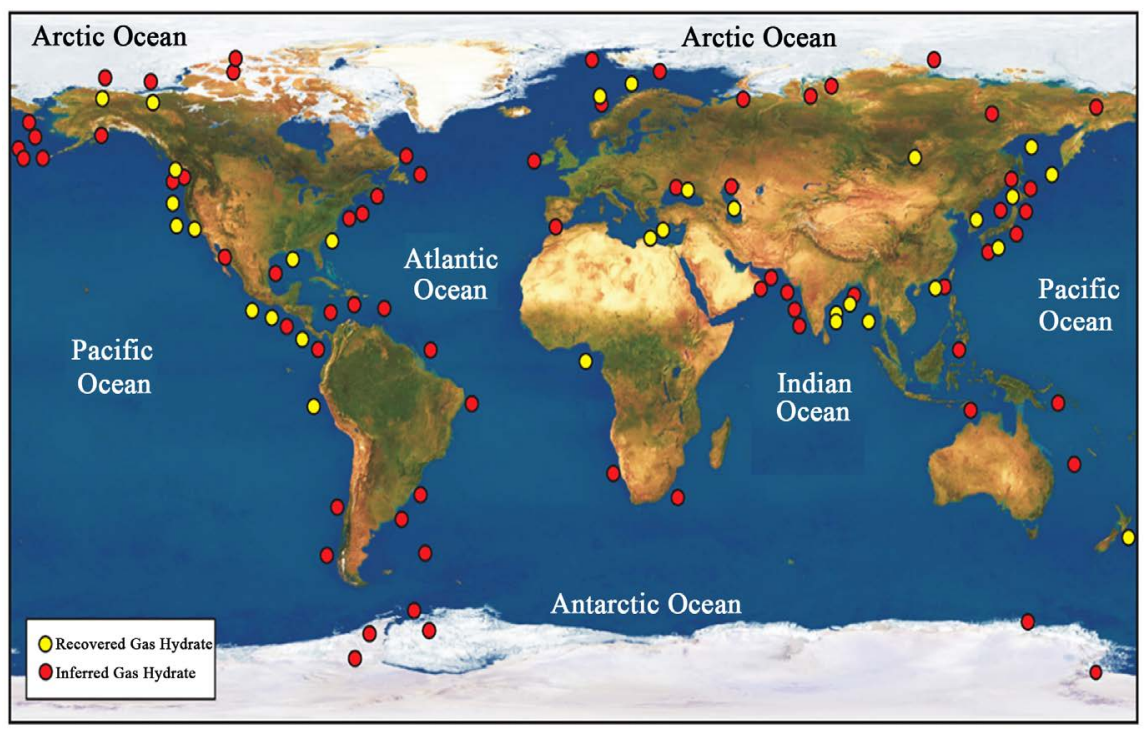

Figure 1. The locations of World methane hydrates [1].

By virtue of the chemical structure, methane hydrate contains more number of hydrogen atoms compared to its conventional counterpart. This stipulates a huge reduction in the production of greenhouse gases such as carbon (IV) oxide, nitrogen (IV) oxide and oxides of sulphur. Presently, the volume of methane hydrate in place is believed to be greater than 2000 trillion cubic meters which is two times the amount of producible lives of conventional reserves.

These gas hydrate reserves though with a prosperous prospect are also hazardous. Previous cases in the past were encountered where it poised drilling hazards to oil and gas expeditions. When gas hydrate stability zone is tampered resulting in gas release, it poses a greater amount of risk to marine lives and production equipments. The occurrence of gas hydrate to become unstable and release methane gas is the same reason, these hazards need to be assessed in order to effectively produce methane gas on a wide scale. Gas hydrates hindered early attempt to plug the Deepwater Horizon Oil Well blowout in the Gulf of Mexico and to siphon the leaking oil and gas to the surface [2].

\section{Gas Hydrates Phase Relations}

The formation of gas hydrate is influenced by conditions such as low temperature, high pressure, free water formation, turbulence and presence of acidic gases. The phase behavior for methane hydrate system is shown in Figure 2.

The equilibrium position of major concern is the Q1 and Q2. These points show the position at which gas hydrate are formed and the point at which they dissociate respectively. At point Q1, four phases are seen to exist in equilibrium. These are hydrate, ice, water, and methane gas. At point Q2, four phases similarly exist and are in equilibrium. These phases are: hydrate, water, methane gas, and liquid hydrocarbon. Point $\mathrm{C}$ is the critical point where the fluid hydrocarbon in three phase forms into a single phase in equilibrium. 


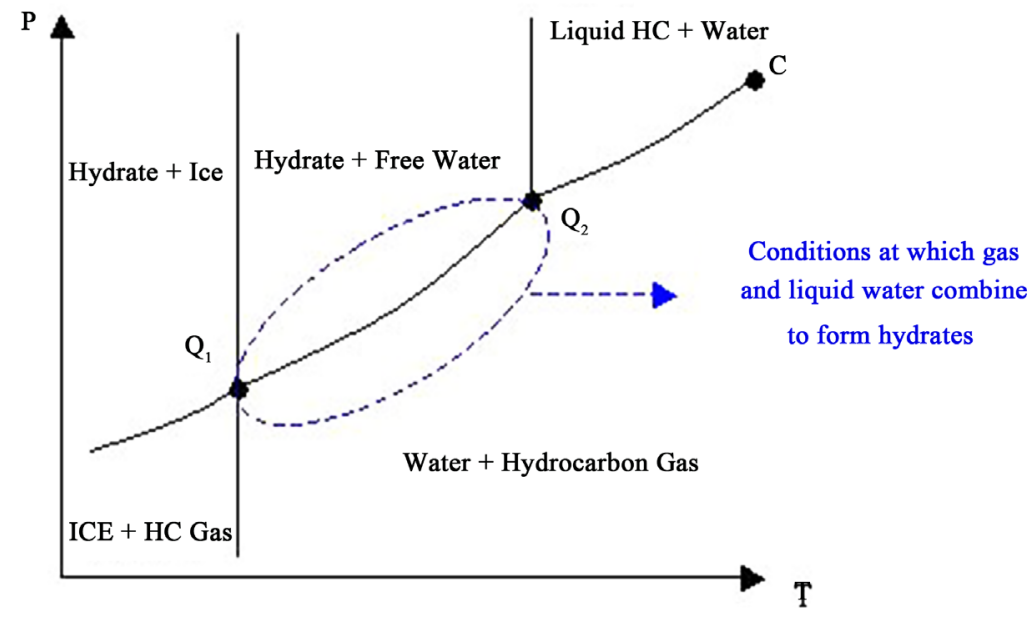

Figure 2. The diagram of methane hydrate phase [3].

\section{Possible Gas Hydrate Production Technique}

Viable production method of gas from methane hydrate has been proposed till date. They all involve causing a dissociation of methane hydrate into methane gas and water. These production methods include steam injection, depressurization, and chemical stimulation. Possible production methods are shown in Figure 3.

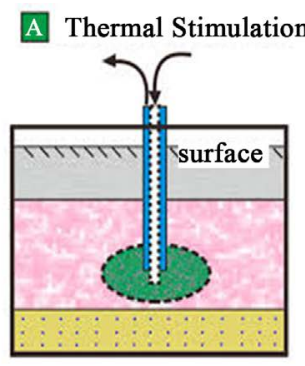

Depressurization
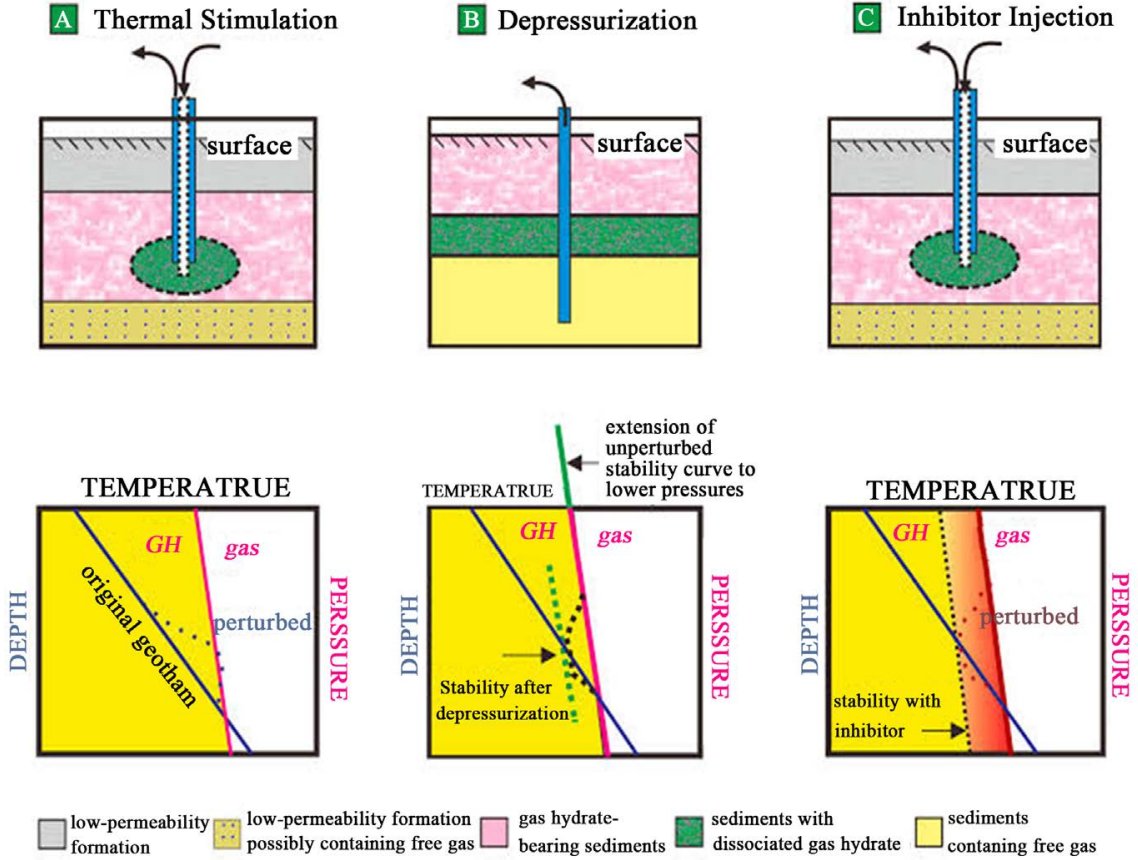

Figure 3. The methods for gas hydrate production [4].

\subsection{Steam Injection}

Steam prepared at the surface is pumped into the wellbore to the perforated casing in order to increase the formation pressure which then alters the equilibrium condition. 


\subsection{Depressurization}

This involves a reduction in the formation pressure. A practical application for this is to pump the drilling mud out of the wellbore to the surface.

\subsection{Chemical Stimulation}

This involves the use of inhibitors such as methanol, ethylene glycol and di ethylene glycol to influence the change in the methane hydrate equilibrium position.

\section{Gas Hydrates in Nankai Trough}

The Japanese Methane Hydrates Research and Development Programs at Nankai Trough releases series of report conducted at Nankai Trough. The report gives the in place volume of gas hydrates energy deposited and the most effective method of production. The research objectives are to understand the existence of gas hydrates present in the Nankai Trough, properties aiding its formation \& stability, possible \& effective production method of gas from methane hydrate, and the environmental implications of producing these novel energy sources. Depressurization methods are used to produce a certain volume of methane gas from methane hydrates. However, this method is used to test the viability of producing methane gas in large scale but not necessarily for wide scale production. The research also notes that methane hydrates are much producible from reservoirs having high values of permeability and porosity.

Possible swift trigger of earthquakes and movement of tectonic plates in Japan originate from activities such as methane hydrates drilling and excavation in the Nankai Trough off the Pacific Coast. This results in Japanese Government holding an enlightment programme for their masses to prepare them for potential earthquakes originating from the Nankai Trough. By virtue of damage estimate done by Japanese Government in 2012, the mortality rate for an earthquake induced from Nankai Trough could be above 320 thousand while that of collapsed and burning buildings shouldn't be less than 2 million.

\section{Gas Hydrates in Mocondo Oil Well in Deepwater Horizon}

The deepwater horizon oil blowout occurred on April 20, 2010 as a result of poor cementation job which caused an influx of formation fluid into the wellbore (kick). The inherent deposition of methane hydrates in the Gulf of Mexico as well as the fact that Mocondo Oil Rig is in a region known for gas hydrates accumulation that prevents the prompt attempt to plug the well initially when the kick began. Some research conducted after the blowout argued that methane hydrate might have caused explosion because of triggers in the equilibrium condition (high pressure and low temperature) during oil drilling. This is quite evident as researches on gas hydrate is ongoing few miles from Mocondo Rig.

The aftermath of the blowout is disastrous as it leads to a complete loss of the drilling rig, loss of manpower, pollution of coastal lives among others. Deepwa- 
ter drilling such as in deepwater horizon is a hazardous activity, as well as the construction of offshore platform such as Mocondo Rig, and equipments used is very complex. Tentative Standard Operating Procedures must be strictly adhered to when drilling under very challenging and hostile conditions as in deepwater horizon.

\section{Potential Hazards Associated with Gas Hydrates Recovery}

The recovery of methane hydrate is influenced by the position of the gas hydrate reserve in the subsurface deposit as well as the geology of that particular formation. Various form of hazards occur during its expedition. These include: deepwater hazard, greenhouse gases, hazards associated with deepwater ecology, and deepwater engineering hazards.

\subsection{Deepwater Hazards}

This is an important hazard whose occurrence is as a result of drilling through the formation containing gas hydrate. It is subdivided into deepwater landslide and natural catastrophe hazard.

\subsubsection{Deepwater Landslide}

This occurs as a result of stress of the underlying gas hydrate formation when the methane hydrate is released above the equilibrium condition (high temperature and low pressure). This results in a corresponding increase in the pore spaces bearing of gas hydrate which releases the gas. The large block of methane hydrate sediments begins to crack and fall off forming a downward slope. This phenomenon is shown in Figure 4.

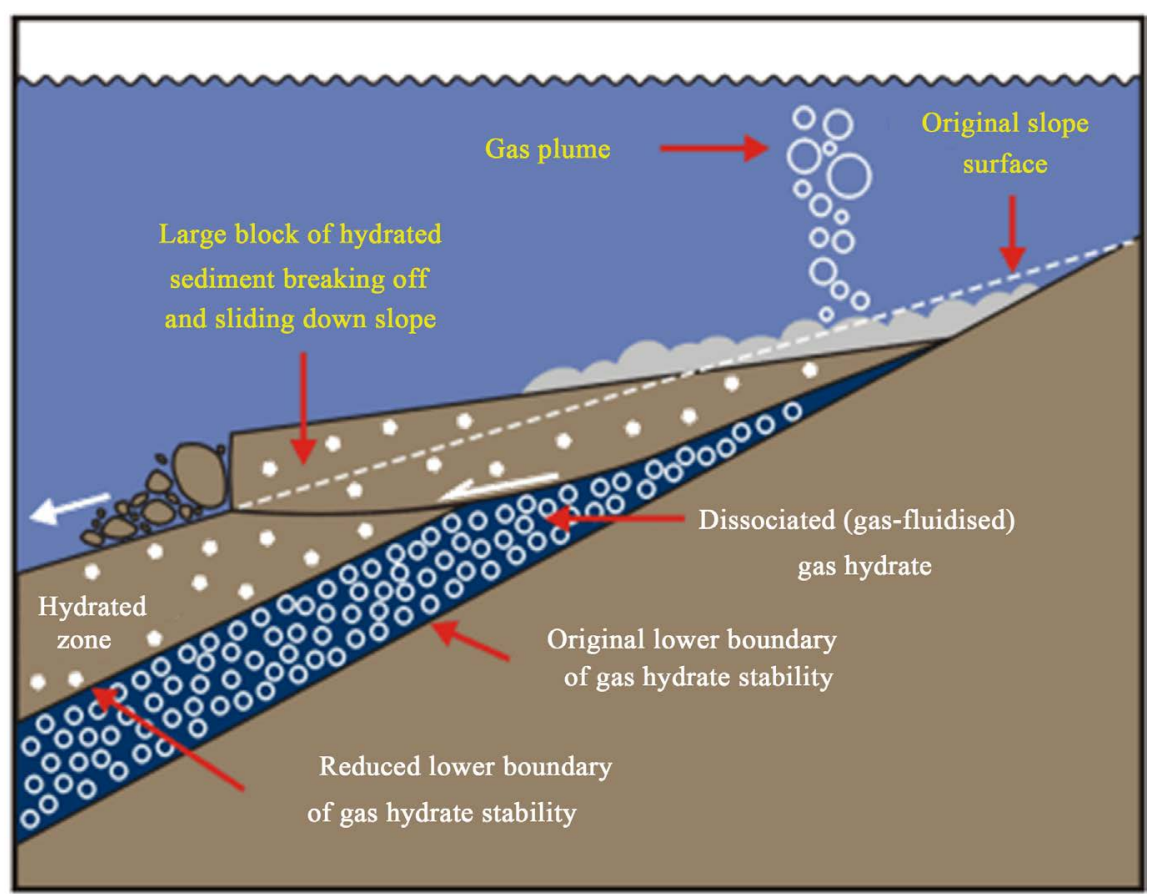

Figure 4. Submarine landslide [5]. 
According to researchers from GEOMAR Helmholtz Centre for Ocean Research Kiel, together with colleagues from Kiel University and the Alfred Wegener Institute, Helmholtz Centre for Polar and Marine Research, have found gas hydrate and submarine landslide are concurrently linked but in a quite different way than previously thought "Our data show that stable gas hydrates can indirectly destabilize the sediment above" says Dr. Judith Elgar from GEOMAR [6].

\subsubsection{Natural Catastrophe Hazards}

The drilling for methane gas hydrate could lead to formation of disasters such as earthquake, turbidity, tsunami, and volcanic eruption as a result of varying change in temperature and pressure conditions, Figure 5 shows concern associated with gas hydrates. In colder regions such as Greenland, an instability causing the ice to melt releases methane gas and large volume of water into the ocean. This effects an "isostatic rebound" that causes the lithosphere to bounce, thereby triggering natural disasters such as earthquakes, volcanoes and many others. When the permafrost previously held things together, we don't expect frequencies of coastal collapse, avalanches and landslides, which can send shockwaves through the sea that in turn trigger earthquakes and hydrate destabilization.

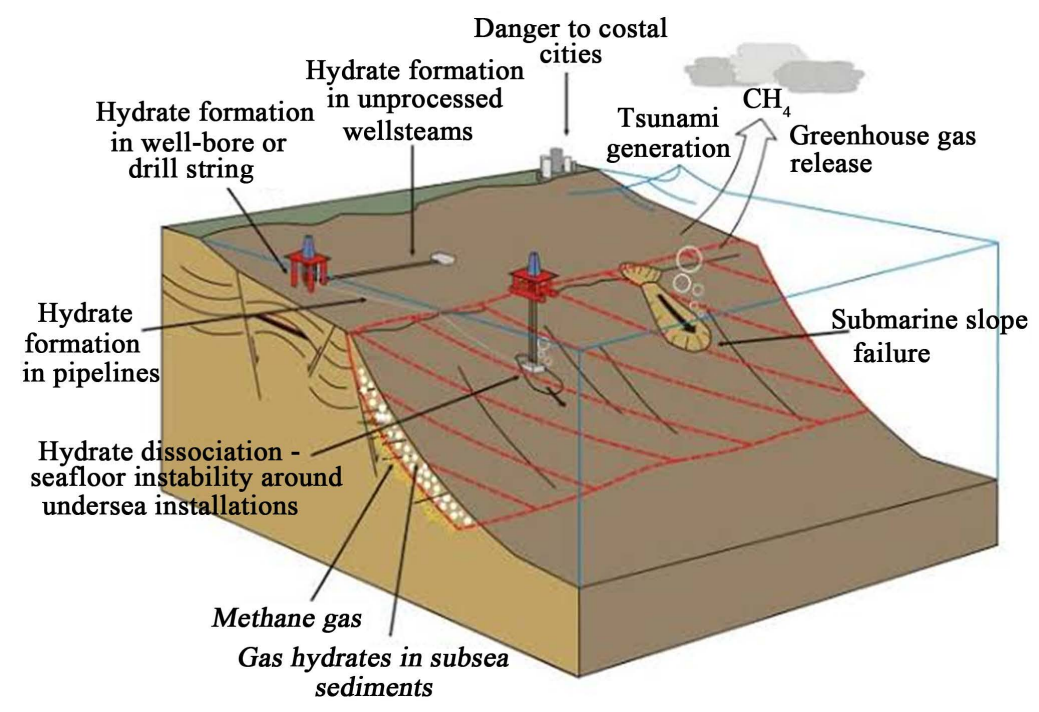

Figure 5. The concern associated with gas hydrates [7].

\subsection{Greenhouse Gases}

The production of methane gas reserve produces gases such as carbon (IV) oxide, sulphur (IV) oxide, and nitrogen (IV) oxide among others which affect our climate change and aid the production of acidic rain in the atmosphere. Global warming can influence hydrate dissociation through increased temperature of the ocean bodies. Therefore, adequate investigation of the impact of greenhouse gases associated with methane hydrate production requires prior attention. 


\subsection{Hazards Associated with Deepwater Ecology}

The increase in pore space which arises from instability during methane hydrate recovery in marine sediment, is possibly caused by drilling activities. The gas seeps through the sediments, therefore affecting marine lives and major marine components. Lack of control of this gas can lead to a disruption of the seabed which causes faulting.

\subsection{Deepwater Engineering Hazards}

During the production of methane hydrate reserves, series of hazards are encountered in the course of drilling, completion and production. The problems associated with gas hydrate hazards are shown in Figure 6.

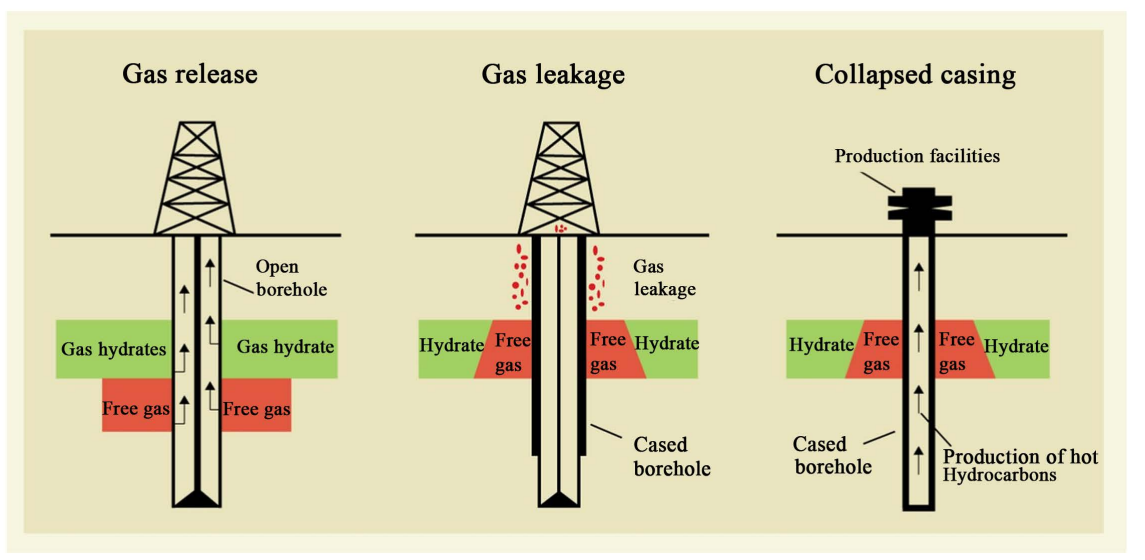

Figure 6. The problems caused by gas hydrate hazards [8].

\subsubsection{Drilling Hazards}

The gas hydrate environments are hostile and pose a challenging condition when drilling through the formation bearing it. As a result of environmental concern and global warming, drilling companies preferably use water based mud in deepwater drilling of methane hydrate. The drilling mud being pumped through the drill string needs to be carefully weighed, balanced and monitored in order to prevent sudden upset of the hydrate stability. While drilling through the methane hydrate zone, the drilling tools could possibly upset the methane hydrate bearing formation which can lead to gases being released to the surface unexpectedly which will pose greater danger. A prevailing hazard using this type of drilling mud is the formation of methane hydrate at the condition such as high pressure and low temperature. This can lead to a gas kick which can cause problems associated with well control and safety. Gas hydrates can form a blockage in the drilling conduit and cause flow assurance problems. Since gas hydrates contain mostly water, the water based mud could lose its water to hydrate formation. This increases the fluid weight and formation of slugs.

\subsubsection{Completion Hazards}

After successfully drilling from the surface to the methane hydrate zone, the next step is to complete the well. This involves a perforation of the already cemented 
and cased well, as well as the insertion of production tubings, packers, and possible method of production which dissociate the methane gas. The dissociated gas rushes into the tubings at a very high pressure which can leak to the surface from the zone in between the cemented casing and the subsurface or even worse cause a blowout. Methane hydrate is one condition that prevented prompt attempt to control the blowout at deepwater horizon in offshore platform. Improper engineering design will induce the alteration of equilibrium condition, while completing the well could cause possible crumbing and collapse of the cemented casing and a terrible aftermath effect at the surface.

\subsubsection{Production Hazards}

This is a very crucial aspect after possibly drilling and completing the well. A major distress of this hazard is the transportation of methane gas from the well head to production facilities. Conditions such as low temperature and high pressure influence the hydrate formation and possible blockage of the pipeline or vessel. Introducing a temperature less than the formation temperature of methane hydrate and lagging of the production equipment should be caused by this hazard. Dehydration and the use of inhibitors such as methanol or ethylene glycol will drastically prevent hydrates in the transfer line.

\section{Prospects}

The world has come to see methane hydrate as a beneficial energy source which can satisfy the future energy demands. Its large reserves coupled with its sustainability has lead the foundation for its research in various research institutes around the world. Gas hydrate production test at the Nankai Trough has proven that this energy source is recoverable and its full scale production is a near-future possibility.

\section{Conclusions}

The spatial distribution of methane hydrate around the globe and the enormous in place volume of its reserves makes it an attractive energy source. The assessment of its hazards is carried out to fully understand this novel energy source and possibly reduce the risk associated with its recovery. Gas hydrates are formed from thermogenic or biogenic matters along with low temperature and high pressure that ensure its equilibrium. Major production proposition involves a possible dissociation of methane hydrate into methane gas and water by the methods such as injecting fluids in the wellbore or depressurization of the hydrate zone.

An important issue concerning the methane hydrate is the geohazards it poses during its deepwater recovery. The primary cause of this hazard is the over pressured gas below the hydrate equilibrium and methane hydrates dissociation. Drilling and production processes can cause an instability in the hydrate bearing formation. A common scenario is that the drill bit causes an increase in temperature of the hydrate zone and changes the physical properties which might lead 
to holocaust gas release and seafloor instability.

\section{Conflicts of Interest}

The author declares no conflicts of interest regarding the publication of this paper.

\section{References}

[1] Council of Canadian Academic (2008) Energy from Gas Hydrates: Assessing the Opportunities and Challenges for Canada.

[2] Congressional Research Service (2013) Gas Hydrate: Resource and Hazard. Specialist in Energy and Natural Resource Policy. https://crsreports.congress.govRS22990

[3] Adewumi, M. (2018) Phase Relations in Reservoir Engineering. Pennstate College of Earth and Mineral Science, Pennsylvania.

http://www.e-education.psu.edu/png520/m21 p3.html

[4] Zhixue, S., et al. (2016) Numerical Simulation of the Depressurization Process of a Natural Gas Hydrate Reservoir: An Attempt at Optimization of Field Operational Factors with Multiple Wells in a Real 3D Geological Model. Energies, 9, 714. http://doi.org/10.3390/en9090714

[5] Central for Gas Hydrate Research (2018) Why Are Gas Hydrate Important? Heriot Watt Institute of Petroleum Engineering, UK.

http://www.pet.hw.ac.uk/research/hydrate/hydrates why.cfm@hy=what.html

[6] Science News (2018) Stable Gas Hydrate Can Trigger Landslide. Helmholtz Centre for Ocean Research Kiel (GEOMAR).

http://www.sciencedaily.com/releases/2018/02/180220161224.htm

[7] Abhinav, G., et al. (2018) Gas Hydrate: Future Energy Source. Department of Petroleum and Earth Science University of Petroleum and Energy Studies. http://www.slideshare.net/mobile/abhitgarg/gas-hydrates-69497564

[8] Collett, T.S. and Dallimore, S.R. (2002) Detailed Analysis of Gas Hydrate Induced Drilling and Production Hazards. Proceedings of the 4th International Conference on Gas Hydrates, Yokohama, Japan, 19-23 April 2002, 63. 